\title{
Гидротермально-вадозные образования зон разломов в Западном Прибайкалье
}

\author{
Базарова Е.П., Савельева В.Б., Рубцова М.Н. \\ Институт земной коры СО РАН, Иркутск, bazarova@crust.irk.ru
}

\begin{abstract}
Аннотация. Приводятся первые результаты изучения измененных пород, приуроченных к древним разломам, заложенным в породах иликтинской свиты в центральной части Байкальского выступа Сибирского кратона. Измененные охристо-кремнистые образования представляют собой пропластки кварца среди охр и кавернозный кварц, пустоты в котором заполнены черной или рыжей охрой, сложенной кварцем и гетитом с примесью хлорита и каолинита. Породы сложены кварцем, окислами железа, слюдами, также отмечаются редкоземельные минералы, рутил, циркон, каолин, доломит, окислы марганца. При окварцевании и серицитизации сланцев происходило накопление $\mathrm{Cu}$, As и $\mathrm{U}$, а формирование кремнисто-охристых метасоматитов сопровождалось накоплением этих и ряда других рудных элементов (Cu, U, As, Co, Ni, Zn, Bi, Мо). Учитывая большое содержание железа в данных образованиях, можно предполагать повышенное содержание перечисленных элементов в изначально сформировавшихся сульфидных залежах.

Ключевые слова: кора выветривания, окварцевание, гидротермально-вадозные образования, охра, сульфиды, серицитизация, Западное Прибайкалье.
\end{abstract}

\section{Hydrotermal-vadose formations of fault zones in the Western Baikal region}

\author{
Bazarova E.P., Savel`eva V.B., Rubtsova M.N. \\ Institute of the Earth 's Crust, Irkutsk, bazarova@crust.irk.ru
}

\begin{abstract}
This paper presents the first results of study of altered rocks, associated with the ancient faults laid at Iliktinskaya formation rock in the central part of Baikal outcrop of the Siberian craton. Altered ocher-siliceous formations are quartz interlayers among ocher and cavernous quartz, where cavities are filled with black and red ocher. The rocks are composed of quartz, iron oxides; micas, rare earth minerals, rutile, zircon, kaolin, dolomite, manganese oxides are also noted. During silification and sericitization of shale, $\mathrm{Cu}$, As and $\mathrm{U}$ accumulated, and the formation of siliceous-ocher metasomatites was accompanied by the accumulation of these and a number of other ore elements $(\mathrm{Cu}, \mathrm{U}, \mathrm{As}, \mathrm{Co}, \mathrm{Ni}, \mathrm{Zn}, \mathrm{Bi}, \mathrm{Mo})$. Given the high content of iron in these formations, it can be assumed that the content of these elements is elevated in the initially formed sulfide deposits.

Key words: weathering crust, silicification, hydrotermal-vadose formations, ocher, sulfide, sericitization, Western Baikal region.

\section{введение}

Гидротермально-вадозные образования зон разломов и ареалов их воздействия, относимые также к древним корам выветривания, были описаны В.Н. Разумовой (Разумова, 1997) как продукты метасоматического выщелачивания, замещения и цементации зоны смешения грунтовых вод с эндогенными эманациями и растворами, поступавшими с глубин по активным крутопадающим разломам фундамента. С такими образованиями связаны различные полезные ископаемые: силикатноникелевые руды, каолины, вермикулиты, минеральные краски, бокситы, железные руды, россыпи и т.д. Древние коры выветривания имеют сложный зонально построенный профиль и в зонах разломов достигают очень большой площади (Разумова, 1997).

В данной работе приводятся первые результаты изучения измененных пород, приуроченных к древним разломам, заложенным в породах иликтинской свиты в центральной части Байкальского выступа Сибирского кратона. Описывается минеральный и химический состав данных образований, а также приводятся гипотезы их формирования.
\end{abstract}




\section{Объект и методъ}

Иликтинская свита палеопротерозоя в районе исследований представлена хлоритсерицитовыми и хлорит-серицит-биотитовыми сланцами, нередко углеродсодержащими и пиритоносными, а также мощными пачками песчаников сходного состава (Федоровский, 1985). Они прорываются гранитами приморского комплекса $\mathrm{PR}_{1}$ и дайками диабазов.

Гидротермальные изменения изучались в обнажениях, расчистках и геологических канавах, пройденных $3 \mathrm{AO}$ «Сибирская геологическая компания» (рис. 1 а).
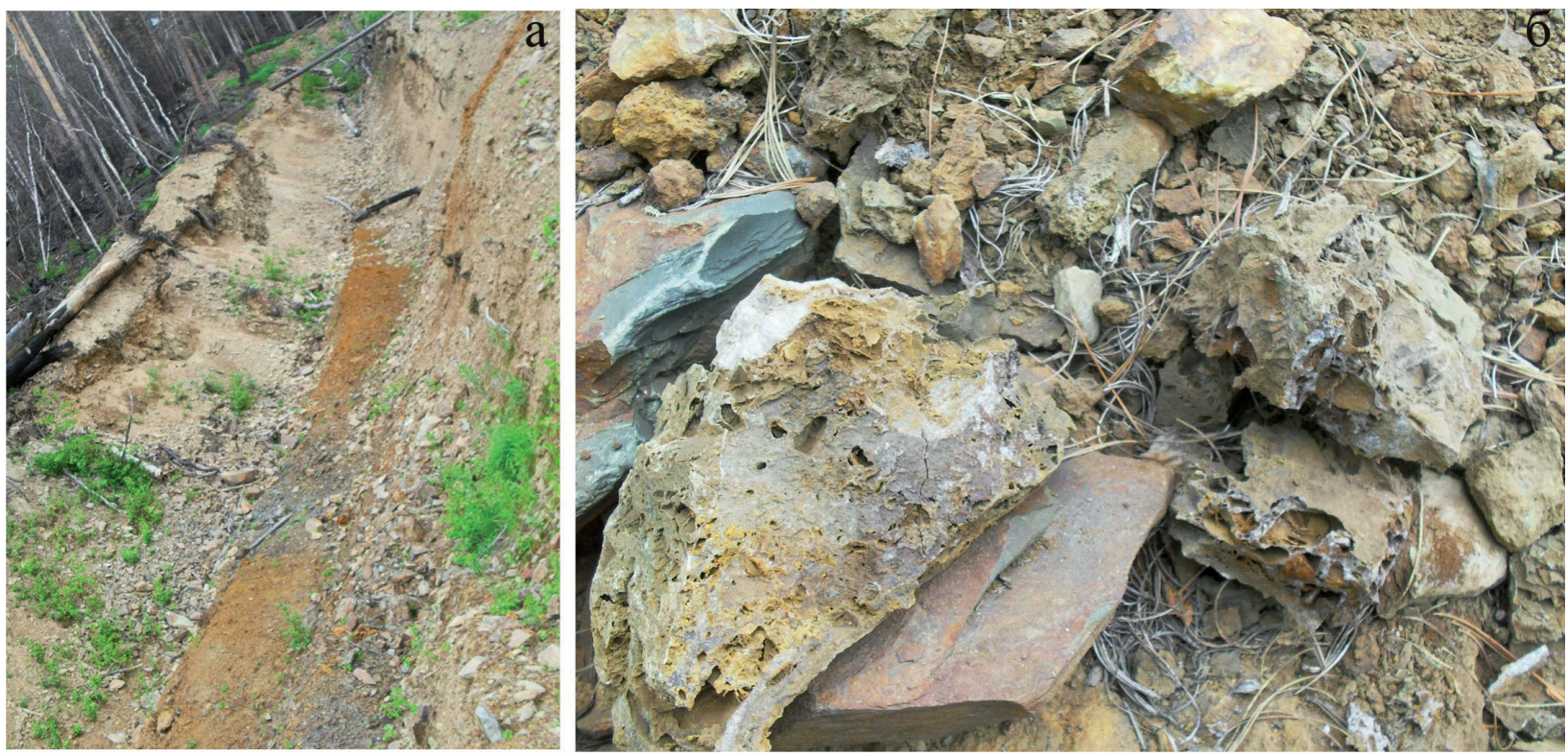

Рис. 1. а - общий вид геологической канавы, вскрывающей гидротермально-измененные породы; б - образцы кавернозного кварца.

Fig. 1. a - general view of the geological ditch, revealing hydrotermally altered rocks; $b$-samples of cavernous quartz.

Гидротермальные изменения приурочены к разломам северо-западного и северо-восточного простираний и представлены зонами осветления в милонитизированных сланцах и пространственно ассоциирующимися с осветленными породами охристо-кремнистыми образованиями. Мощность осветленных пород достигает десятков метров; участки наиболее интенсивного осветления, представленные тонкозернистыми серицит-кварцевыми и кварц-серицитовыми, нередко с пиритом, метасоматитами, имеют мощность 1-3 м. Среди кварц-серицитовых метасоматитов наблюдаются кварц-гематитовые метасоматиты с гематитом в виде красной порошковатой массы. Мощность зон обохрения достигает 50 м. Гидротермально-измененные породы имеют вид рыхлых рассыпчатых образований черного, желтого, бурого и кирпично-красного цвета, сложенных кварцем, слюдой и гетитом.

Минеральный состав охристо-кремнистых образований был определен в ЦКП Института земной коры СО РАН в г. Иркутске методом порошковой дифракции на рентгеновском дифрактометре ДРОН - 3.0, излучение - CuK $\alpha, \mathrm{Ni}$ - фильтр, $\mathrm{V}=25$ кВ, I = 20 мА, в диапазоне 3 - $65^{\circ} 2 \theta$, шаг сканирования $-0.05^{\circ}$. Фазовый состав проб расшифрован с помощью программы поиска фаз. Дополнительно проведено измерение некоторых проб с целью идентификации фаз глинистых минералов. Для решения задачи осуществляли подготовку ориентированного материала пробы осаждением глинистой фракции на стеклянной подложке, прогреванием при температуре $550^{\circ}$ в течение 3 ч., и насыщением этиленгликолем. Диагностика минералов и изучение их химического состава проводились с использованием электронного сканирующего микроскопа «LEO-1430VP» (Carl Zeiss International) с энергодисперсионным спектрометром «INCAEnergy 350» (OxfordInstruments Analytical Ltd.). Анализы выполнены Е.А. Хромовой и Е.В. Ходыревой в Геологическом институте СО РАН (г. УланУдэ); условия анализа: ускоряющее напряжение 20 кВ, ток зонда 0.3-0.4 нА, размер зонда $<0.1$ мкм, 
время измерения 50 сек. Химический состав пород определялся в ЦКП «Геодинамика и геохронология» Института земной коры СО РАН в г. Иркутске методом силикатного анализа (аналитик Самойленко М.М.) и РФА анализа (аналитики Е.В. Худоногова, С.И. Штельмах, Н.Н. Володина).

\section{Минералогия и геохимия гидротермально-измененных пород}

Кремнистые образования представляют собой пропластки кварца среди охр мощностью до нескольких сантиметров и кавернозный кварц, образующий желваки размером до 10-15 см. Пустоты в кварце обычно заполнены черной или рыжей охрой (рис. 1 б). Образец рыжей охры из пустот в кавернозном кварце сложен кварцем, магнетитом, хлоритом и мусковитом. Магнетит представляет собой остроугольные обломки среди кварца и хлорита (рис. 2 в).
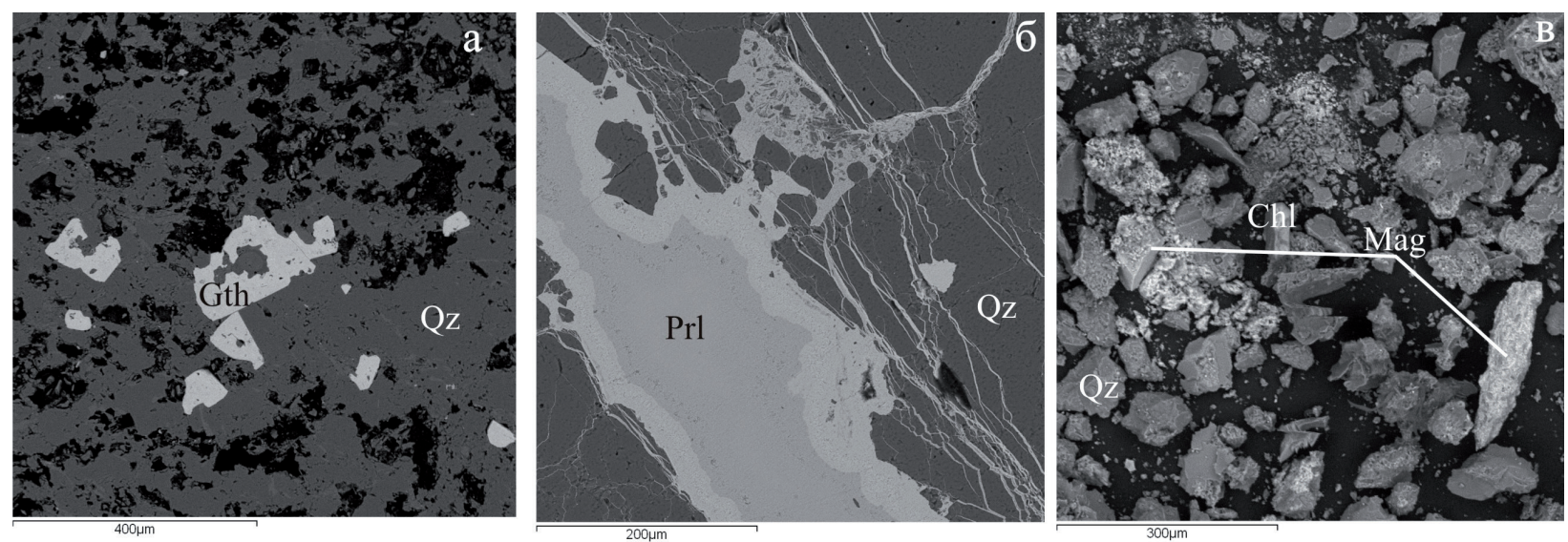

Рис. 2. Фотографии образцов гидротермально-измененных пород (а, б) и охры из пустот в кавернозном кварце (в). Qz - кварц, Gth - гетит, Prl - пиролюзит, Chl - хлорит, Mag -магнетит.

Fig. 2. Photographs of samples of hydrothermally altered rocks ( $a, b)$ and ocher from voids in cavernous quartz (в). Qz - quartz, Gth - goethite, Prl - pyrolusite, Chl - chlorite, Mag - magnetite.

Отмечались также образования с губчатой текстурой, весьма тяжелые, сложенные гетитом и рентгеноаморфными фазами. Кроме того, гетит присутствует в виде тонких (до 0.5 см) кор и сливных масс на поверхности вмещающих пород. В канавах наблюдается зональность: сланцы сменяются обохренными сланцами, затем обохренным кварцем и рыжими и черными охрами; чернокварцевые песчаники сменяются рыжими охрами и черными охрами с прослоями кварца; диабазы переходят в измененные диабазы и обохренный кварц. Были изучены образцы измененных диабазов, песчаников, сланцев, кавернозного кварца, охр из пустот в кавернозном кварце, железистых образований губчатой текстуры, а также обохренных образований, о которых нельзя сказать однозначно, по какой породе они сформировались. Вследствие сильного ожелезнения и дальнейшего выветривания в поверхностных условиях измененные породы зачастую представляют собой мягкие рыхлые обохренные разности.

Общим для всех гидротермально-измененных пород является присутствие кварца, в котором находятся прожилки и включения гетита, иногда сохранившие правильную форму исходных кристаллов пирита (рис. 2 a). Также гетит может образовывать небольшие прожилки и включения в хлорите. В кварце и гетите встречаются прожилки и включения слюд. Пиролюзит образует прожилки в кварце, причем отмечается увеличение содержания $\mathrm{BaO}$ от центра к краю прожилка (рис. 2 б). Зачастую отмечаются редкоземельные минералы: монацит (в кварце, гетите, цирконе, хлорите и мусковите), ксенотим (в гетите и мусковите), рутил (в кварце, хлорите, мусковите и окислах железа), циркон (в кварце и мусковите), каолин, доломит.

Так как данные образования имеют смешанное происхождение, была сделана попытка исследовать их с помощью петрохимических генетических модулей (Юдович, Кетрис, 2000). Использовались следующие модули: гидролизатный модуль $\Gamma \mathrm{M}=\left(\mathrm{TiO}_{2}+\mathrm{Al}_{2} \mathrm{O}_{3}+\mathrm{Fe}_{2} \mathrm{O}_{3}+\mathrm{FeO}+\mathrm{MnO}\right) / \mathrm{SiO}_{2}$; тита- 
новый модуль $\mathrm{TM}=\mathrm{TiO}_{2} / \mathrm{Al}_{2} \mathrm{O}_{3}$; модуль нормированной щелочности $\mathrm{HKM}=\left(\mathrm{Na}_{2} \mathrm{O}+\mathrm{K}_{2} \mathrm{O}\right) / \mathrm{Al}_{2} \mathrm{O}_{3}$; железный модуль ЖМ $=\left(\mathrm{Fe}_{2} \mathrm{O}_{3}+\mathrm{FeO}+\mathrm{MnO}\right) /\left(\mathrm{TiO}_{2}+\mathrm{Al}_{2} \mathrm{O}_{3}\right)$ (мас. \%). По значениям гидролизатного модуля ГМ исходные сланцы (ГМ от 0.3 до 0.45 ) относятся к нормосиаллитам, измененные обохренные разности, которые имеют ГМ 0.87-7.2, относятся к супергидролизатам. Те и другие породы имеют нормальную титанистость (ТМ 0.04-0.06) и нормальную и пониженную щелочность (НКМ 0.08-0.33). Модуль ЖМ для исходных сланцев имеет невысокие значения от 0.36 до 0.51 , что относит данные породы к норможелезистым, но изменяется в широких пределах от 45 до 115 для обохренных разностей, которые можно отнести к гипержелезистым.

В целом, для кремнисто-охристых образований характерны высокие концентрации $\mathrm{Fe}_{2} \mathrm{O}_{3}-$ до 70-90 мас. \% и $\mathrm{MnO}$ до 5 мас. \%, а также $\mathrm{Zn}$ - до 7500 г/т, $\mathrm{Cu}$ - до 1100 г/т, $\mathrm{Ni}$ - до 800 г/т, Со - до 640 г/т, As - до 2.9 мас. \%, Мо - до 70 г/т, Вi - до 12 г/т, U - до 24 г/т.

Для удобства анализа полученных данных были рассчитаны средние содержания концентраций элементов в образцах прокварцованных сланцев, кварц-серицитовых метасоматитов и обохренных разностей, а затем нормированы на средний состав исходных пород и представлены на графике (рис. 3) в виде относительных концентраций элементов.

При окварцевании сланцев происходит вынос практически всех петрогенных окислов, кро-
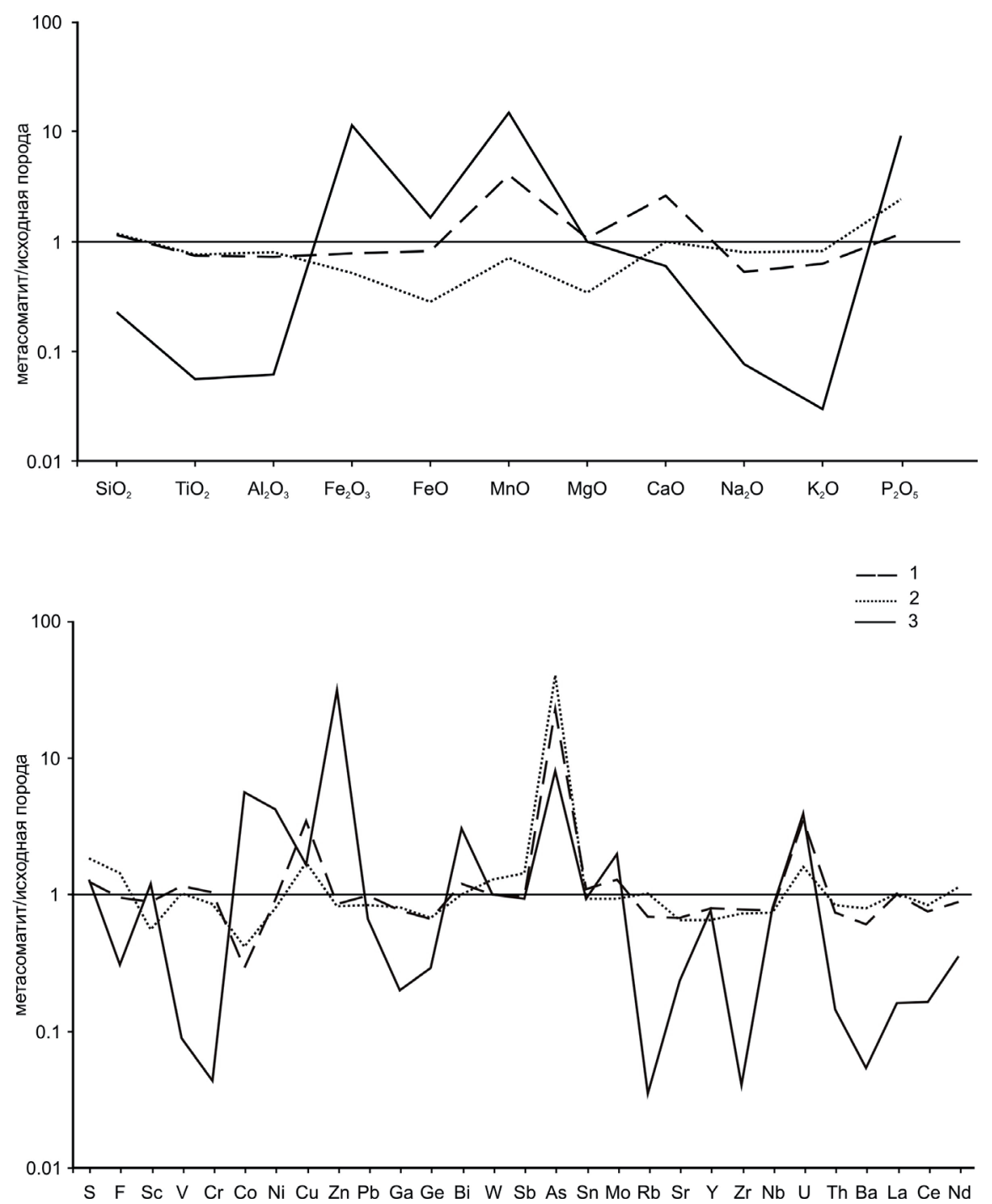

Рис. 3. Нормирование состава измененных пород (метасоматитов) относительно неизмененных сланцев (1 - прокварцованные сланцы, 2 - кварц-серицитовые метасоматиты, 3 - кремнисто-охристые метасоматиты).

Fig. 3. Rationing of the composition of altered rocks (metasomatites) regarding unaltered shales (1 - quartzed shales, 2 - quartz-sericite metasomatites, 3 - siliceous-ocher metasomatites). 
ме $\mathrm{SiO}_{2}, \mathrm{MnO}, \mathrm{CaO}$ и $\mathrm{P}_{2} \mathrm{O}_{5}$, а содержание $\mathrm{MgO}$ остается на прежнем уровне. Из элементов-примесей интенсивно выносится Со, менее интенсивно - $\mathrm{Ga}, \mathrm{Ge}, \mathrm{Rb}, \mathrm{Sr}, \mathrm{Y}, \mathrm{Zr}, \mathrm{Nb}$, Th, Ba, Ce, Nd; накапливаются $\mathrm{Cu}, \mathrm{U}, \mathrm{As}$, в меньшей степени - V, Bi, Мо. При образовании кварц-серицитовых метасоматитов выносятся все петрогенные окислы, кроме $\mathrm{SiO}_{2}, \mathrm{P}_{2} \mathrm{O}_{5}$, а содержание $\mathrm{CaO}$ не меняется. Поведение элементов-примесей сходно с тем, что наблюдается для окварцованных сланцев, незначительно накапливается F и S. При образовании кварц-гематитовых метасоматитов (кремнисто-охристых образований) инертным остается $\mathrm{MgO}$, интенсивно выносятся $\mathrm{SiO}_{2}, \mathrm{TiO}_{2}, \mathrm{Al}_{2} \mathrm{O}_{3}, \mathrm{Na}_{2} \mathrm{O}, \mathrm{K}_{2} \mathrm{O}$, менее интенсивно - $\mathrm{CaO}$, и интенсивно накапливаются $\mathrm{Fe}_{2} \mathrm{O}_{3}, \mathrm{FeO}, \mathrm{MnO}, \mathrm{P}_{2} \mathrm{O}_{5}$. Что касается элементовпримесей, то происходит сильный вынос $\mathrm{V}, \mathrm{Cr}, \mathrm{Ga}, \mathrm{Ge}, \mathrm{Rb}, \mathrm{Sr}, \mathrm{Zr}, \mathrm{Th}, \mathrm{Ba}, \mathrm{La}, \mathrm{Ce}, \mathrm{Nd}$, в меньшей степени - Pb, Y, а также F; накапливаются Co, Ni, Zn, As, U, в меньшей степени - Cu, Bi, Mo.

\section{Заключение}

В целом можно говорить о сходном минеральном составе всех кремнисто-охристых гидротермально-измененных пород, независимо от состава исходных пород. Обохренность - частый результат поверхностного выветривания, но кварцевые образования среди охристых выглядят загадочно. Мощное окварцевание, по-видимому, указывает на переработку гидротермальными растворами этих зон, что согласуется с приуроченностью охристо-кремнистых образований к разломам и пространственной ассоциацией с зонами серицитизации, окварцевания и гематитизации. Что касается генезиса охристых образований с обилием гетита, то это могут быть либо линейные коры выветривания по ранее сформировавшимся в зонах разломов сульфидным рудам, либо продукты переотложения железа и марганца, выносимых из зон окварцевания и серицитизации. При окварцевании и серицитизации сланцев происходило накопление $\mathrm{Cu}$, As и $\mathrm{U}$, а формирование кремнисто-охристых метасоматитов сопровождалось накоплением этих и ряда других рудных элементов (Cu, U, As, Co, Ni, Zn, Bi, Mo). Учитывая большое содержание железа в данных образованиях, можно предполагать повышенное содержание перечисленных элементов в изначально сформировавшихся сульфидных залежах.

Мы предполагаем, что данные кремнисто-охристые образования могли формироваться в период тектоно-магматической активизации южной части Сибирского кратона, сопровождавшейся воздыманием отдельных блоков земной коры, когда в глубинных частях зон разломов под воздействием горячих кислых сульфатных растворов проявились процессы кислотного выщелачивания и были образованы сульфидные залежи, а в зоне перехода от гипогенного режима к гипергенному, в более окислительных условиях, вместо пирита возникали гидроокислы железа (Метасоматизм.., 1998); либо первоначально сформированные сульфидные залежи были выщелочены и переработаны метеорными водами. Накопление $\mathrm{Cu}, \mathrm{U}, \mathrm{As}, \mathrm{Co}, \mathrm{Ni}, \mathrm{Zn}, \mathrm{Bi}, \mathrm{Mo}$ происходило, по-видимому, в сульфидах, а при выщелачивании сульфидов данные элементы сохранялись в гетите.

Работа выполнена при финансовой поддержке РФФИ, проект № 17-05-00819.

\section{Литература}

1. Метасоматизм и метасоматические породы. Под ред. В.А. Жарикова, В.Л. Русинова. М. Изд-во: Научный мир. 1998. 492 с.

2. Разумова В.Н. Древние коры выветривания и гидротермальный процесс. М. Изд-во: Наука. 1997. 156 с.

3. Федоровский В.С. Нижний докембрий Байкальской горной области (геология и условия формирования континентальной коры в раннем докембрии). М. Изд-во: Наука. 1985. 200 с.

4. Юдович Я.Э., Кетрис М.П. Основы литохимии. СПб. Изд-во: Наука. 2000. 479 с. 